\title{
Disparities In Social Development \& Status of Women In Bimaru / Eag States Of India
}

\author{
K. Khanna (Kamini Khanna), D. Patil (Dattajirao Patil)
}

Guru Nanak Institute of Management studies, King Circle, Matunga.

Original Article

Mumbai. India.

\section{E-mail address:}

kaminiptk@gmail.com

\section{Reprint address:}

Kamini Khanna

Guru Nanak Institute of Management studies

King Circle, Matunga

Mumbai 400019

India

Source: Clinical Social Work and Health Intervention

Pages: $28-37$

Volume: 11

Issue: 4

\section{Reviewers:}

Michael Costello

University of Scranton School of education, USA

Gabriela Lezcano

University of California, San Francisco, USA

\section{Keywords:}

Bimaru. Eag. Mgnregp.

\section{Publisher:}

International Society of Applied Preventive Medicine i-gap

CSWHI 2020; 11(4): 28 - 37; DOI: 10.22359/cswhi_11_4_04 (C) Clinical Social Work and Health Intervention

\section{Abstract:}

The problem of Regional disparities in the level of economic development is almost universal. Its extent may differ in different economies. But its existence can hardly be challenged seriously in any country of respectable size. The achievement of Empowered Action Group (EAG) states (Bihar, Jharkhand, Madhya Pradesh, Chhattisgarh, Rajasthan, Orissa, Uttar Pradesh and Uttarakhand) in the area of social sector indicators have not come up to the desired level. Since Mid 1980's Ashish Bose 'BIMARU' still prevailed. The study revealed that overall female literacy has shown strong correlation with indicators of development, means low income persist but amidst all the shortcomings, the female literacy can drag these states on the path of development with a healthy labor force. More emphasis 
should be laid on female literacy programs so that these states can also be pulled out of abject poverty. Although Government has stated „Beti Padyoo Beti Bachoo“ and Sarv Shiksha Abhiyan/Right To Education, But ground realities are too far from the slogan given by the Government.

\section{Introduction:}

India's misfortune during the British rule was not only confined to the backwardness of the masses and increasing unemployment, under-employment and disguised unemployment but also accentuation of uneven spatial development caused by the colonial policy. Consequently, after independence, India emerged as a federation of a few relatively rich and industrialized states along with many poor states which subsisted mainly on agriculture with primitive techniques and semi-feudal agrarian relations 1 .

There is growing concern over the developing regional disparity in the country. The lagging regions complain of neglect and demand special care to attend to their specific problems 2 . It is interesting to note that while planning models in India have become fairly sophisticated in relation to inter-temporal phasing and perspective planning, there has been no comparable extension of analysis to question spatial planning3. No single country would be regarded as having a well-integrated economy as long as glaring disparities exist between the levels of development and standards of living among its different regions.

Indian economy witnessed good growth in the post liberalization era but these high growth rates instead of decreasing inter-personal dispar- ities has more or less widened them leading to social unrest among masses in many states of the country. These glaring disparities often threaten the political and economic stability of the country. The problems of regional and inter-personal disparities are vulnerable to generate discontent and disbelief and may endanger the very integrity of the country. No development is possible in the midst of social tension and civil disturbance.

In the mid 80s, economist analyst Ashish Bose 4 coined an acronym BIMARU, in a paper submitted to then Prime Minister Rajiv Gandhi. BIMARU has a resemblance to a Hindi word „Bimar" which means sick. This was used to describe the bad state of economy in the backward states of Bihar, Madhya Pradesh, Rajasthan, and Uttar Pradesh. BIMARU is an acronym formed from the first letters of the names of the states. Later Odisha was included in the list resulting in the name BIMAROU. Several studies, including those by the UN, showed that the performance of the BIMARU states affected the GDP growth rate of India. Some of these states are also red corridor.

The difference in economic and population growth rates between the BIMARU states and other Indian states sharpened over the 1990s. The economy of four BIMARU states grew at an av-

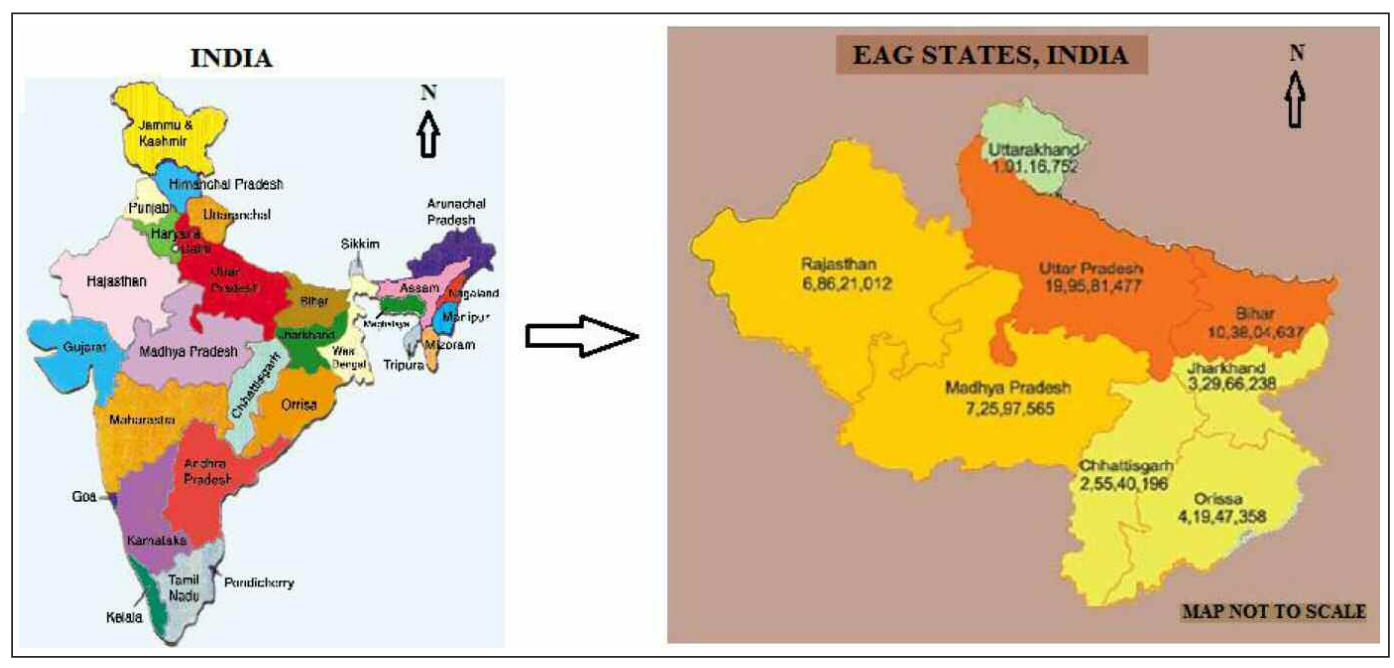


erage of $4.6 \%$ per year in the 1990 s, compared to $6.5 \%$ per year for India as a whole. Since population growth in the BIMARU states was much higher than the Indian average in this period, the income disparity between the BIMARU states and India as a whole also increased5. The government had constituted an Empowered Action Group (EAG) under the Ministry of Health and Family Welfare following 2001 census to stabilize population in eight states (called EAG states) that were lagging in containing population. As per the latest census, EAG states Bihar, Jharkhand, Uttar Pradesh, Uttarakhand, Rajasthan, Madhya Pradesh, Chhattisgarh and Odisha have shown little improvement. They cover over $45 \%$ of India's population.

\section{This research paper focuses on disparities in BIMARU states.}

Inter-state comparison with respect to certain indicators has been used to shed light on the subject. Apart from highlighting the position of different states with respect to certain indicators, an attempt has been made to examine the correlation between different indicators of development (23 indicators: 12 related to the overall social sector development; 11 indicators related to status of women). These include social as well as economic indicators. The study focuses on trends of growth in different social indicators in under-developed states (BIMARU OR EAG) which include development indicators in: literacy; life expectancy; infant mortality; death rate; growth rate of population; birth rate; sex ratio (0-6 years); safe drinking water households; number of PHC, CHC (Primary Health Centers and Child Health Care Centers) and sub-districts under NRHM (National Rural Health Mission); anemia in women; ; economic indicators include per capita net state domestic product at current prices; vocational training, poverty \& headcount ratios; Financial inclusion. To explain the study in a meaningful way, we have included several indicators related to women empowerment. These are: desire to limit child bearing; prevalence of severe anemia in women; percentage of women age 1549 below $145 \mathrm{~cm}$ (nutritional status of women); percentage of women who want more sons than daughters; percentage of experience of physical or emotional or sexual spousal violence; percentage of women with Marriage age before 18 years; total fertility rate; share of women in employment under MGNREGA (Mahatma Gandhi National Rural Employment Guarantee Act).

\section{Study Area:}

The most conspicuous features of the demographic characteristics of the EAG states (former BIMARU states) are its: high fertility; high Infant Mortality Rate (IMR); high Maternal Mortality Rate (MMR); high population growth rate; low literacy rate; high „Gender Literacy Differential“". The plains of Ganga, Yamuna, Narmada, Mahanadi presently supports near about two thirds of the population of the region which is also a high density region. The population of the region in 1951 was only 13.43 million. In 2011 the region had a population of 555.175 million indicating a decadal growth rate of near $25 \%$ on the face of national decadal growth rate of 17.7 $\%$. The population growth rate varies from state to state. The highest decadal growth rate was seen in the state of Bihar of $25.4 \%$ than the National Average. The uneven distribution of population is mainly due to diverse physiographic conditions and disparity in the socio-economic development that the region has experienced in recent decades. The high population growth rates are attributed to the high fertility rate in this region. This phenomenal increase in population has great impact, not only on the demographic composition of the region but also has serious socioeconomic consequences which get reflected in political turmoil and consequent conflicts witnessed in the entire region. An attempt has been made in this study to examine: the determinants for this unusually high population growth rate; the present distribution pattern; some demographic, socio-economic and environmental implications arising out of these.

\section{Objectives:}

1. To analyse the present condition of Empowered Action Group states with respect to socio economic indicators.

2. To find the relation of literacy with respect to social sector indicators.

3. To analyse the status of women in Empowered Action Group states.

4. To study relative aspects of the women's literacy rate among Empowered Action Group states. 


\section{Data Base and Methodology:}

This paper is based on secondary data. To analyse the objectives, data regarding literacy, sex ratio and other demographic variables of EAG states are gleaned from The Census of India (2011), planning commission report of March 2012-13, 2014-15, 2016-17; Sample Registrar Statistics 2010, 11, 12, 13, 14 National Family Health Survey-3; Family welfare statistics 201112; and Economic Survey 2012-13, 14-15, 1617.

The condition of inequality in different social sector development indicators in the BIMARU states is sought to be explained with the help of a coefficient of variation. The trends in coefficient of variation are ascertained to study the direction in regional disparities with respect to particular indicators over the period of time. Sampath6 (1977) used this technique to measure regional disparities. The co-efficient of variation is ascertained as follow:

$$
C V=\frac{\mathrm{S}}{\mathrm{X}} \times 100 \%
$$

Where, C.V = coefficient of variation, $S=S t a n-$ dard Deviation, $\mathrm{X}=$ Mean

To find the relation between overall literacy vis-à-vis female literacy with respect to social sector indicators, the coefficient of correlation is used. The coefficient of correlation is denoted by the symbol ' $r$ ', it is one of the very few symbols that are used universally for describing the degree of correlation between two series. The formula for computing Correlation ' $r$ ' is;

$$
r_{(x, y)}=\frac{\operatorname{cov}(x, y)}{S_{x} S_{y}}
$$

$r_{(x, y)}=$ correlation of the variables $x$ and $y$

$C O V_{(x, y)}=$ covariance of the variables $x$ and $y$

$s_{x}=$ sample standard deviation of the random variable $x$

$\mathrm{s}_{\mathrm{y}}=$ sample standard deviation of the random variable $y$

Further to check the relationship between variables are significant or not, we are applying t-test statistics
Formula for the $t$ test the Correlation Coefficient

$$
\mathrm{t}=\mathrm{r} \sqrt{\frac{\mathrm{n}-2}{1-\mathrm{r}^{2}}}
$$

with degrees of freedom equal to $n-2$.

So there are large numbers of the techniques and methods through which the extent of disparities can be measured and degree of correlation between two series can be found out.

\section{Results}

In this paper a comparison has been made in the level of social-sector development among EAG states (Bihar, Madhya Pradesh, Orissa, Rajasthan, Uttarakhand, Jharkhand, Chhatisgarh and Uttar Pradesh). The study discerns whether the level of literacy in EAG states has any correlation with social indicators like: life expectancy; infant mortality; total death rate; growth rate in population; sex ratio (0-6 years); safe drinking water; number of $\mathrm{PHC}$ and $\mathrm{CHC}$ and sub districts under NRHM; anemia in women. Apart from these social indicators, the economic indicators such as: per capita net state domestic product at current prices; vocational training; poverty headcount ratio; financial inclusion has any relation with literacy rate; whether level of literacy affects any of these indicators positively or not. A general contention is that literacy plays a major role in economic development of any society or region. Since independence, these underdeveloped states have been more or less in same plight despite efforts by government to reduce disparities through 5-year plans. The present incumbent government's motto of inclusive growth also gives more or less a shady picture. It is found (Table 1) in the study that Bihar which is having a low level of literacy of $63.82 \%$ as compared to national average $(74.04 \%)$; or average of EAG states (70.37) had a negative correlation with life expectancy (-.255); birth rate (-.242); sex ratio ($.245)$; growth rate of population (-.646); number of $\mathrm{PHC}, \mathrm{CHC}$ and other sub-districts under NRHM (-.258). It means that, there is low degree of negative correlation. Same is the case with all other backward states which have also shown a low degree of negative correlation with above mentioned indicators related to overall social sector development. It is important to mention that among all the above mentioned indicators, 
growth rate of population has a moderate negative correlation with overall literacy. It means, with the increase in education level, this indicator shows declining trend and this is a positive trend for the economy. On the other hand, infant mortality; death rate; vocational training institutes; financial inclusion; per capita NSDP; poverty head count ratio; safe drinking water revealed a positive correlation. The only single indicator i.e., per capita NSDP which shows high degree of positive correlation with overall literacy $(0.859)$, may be the reason that these underdeveloped states are also the pockets from where migration of labor, or work force is to other states like Bihar Uttar Pradesh are major labor migrating hubs in the country. So their contribution to their own state is high.

Further, the other important indicator, which has shown a positive result when related to literacy, was infant mortality rate. The study reveals that the states which have a low literacy rate have a high infant mortality rate. So, literacy plays a positive role in decreasing the infant mortality rate. While in other indicators its role remains dubious. So we can say that apart from literacy there are certain social factors which play a dominant role in case of other indicators which are showing a low degree of negative correlation with literacy. Overall sex ratio (0-6 years) turned out to be very disappointing in Rajasthan (888) and Uttarakhand (890). These figure even turned out to be even less than both combined average of EAG states (924) and at the national level (918). In fact, the poor sex ratio is a reflection of maladies in the society.

Discrimination of gender at the family level and at the social level is the root cause of such an unfavorable sex-ratio. Higher female mortality in different age group is also responsible for the low sex ratio. Female infanticide and neglect lead to high female mortality and thus a decline in the sex ratio. Further, under counting of females in different census; neglect of the girl child; frequent child bearing; discrimination against females are some other causes of the low sex ratio7.

It was observed that, those states having more vocational training programs, have more financial inclusion. For example, in U.P, M.P vocational institutes are higher (294 and 99 respectively) and second highest among EAG states and also these states have higher financial inclusion.

Though, overall literacy shows positive correlation with some social sector indicators and negative correlation with other social sector indicators, a close analysis and bifurcation of literacy rate between male and female has given glaring results. 
Table 1 Social Sector Development in BIMARU States Year 2016-17

\begin{tabular}{|c|c|c|c|c|c|c|c|c|c|c|c|c|c|}
\hline \begin{tabular}{l}
$\frac{y}{ \pm}$ \\
$\stackrel{ \pm}{\tilde{n}}$ \\
\multirow{n}{*}{}
\end{tabular} & 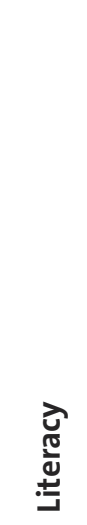 & 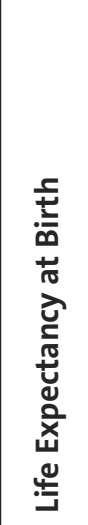 & 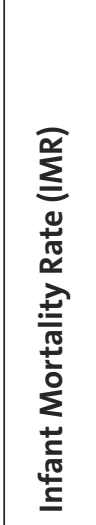 & 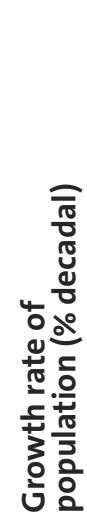 & 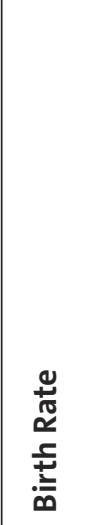 & 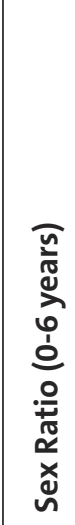 & 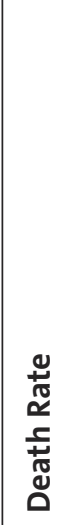 & 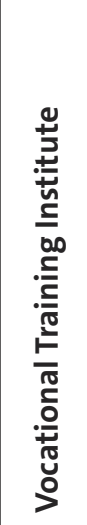 & 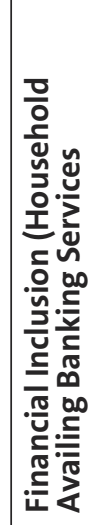 & 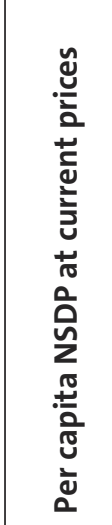 & 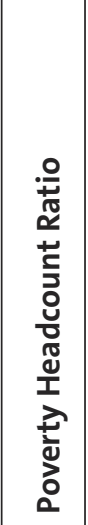 & 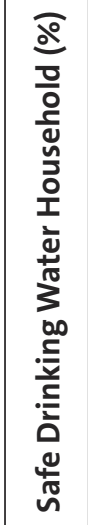 & 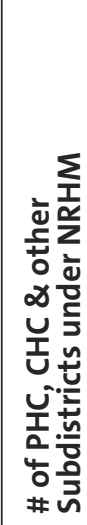 \\
\hline Bihar & 63.82 & 67.7 & 42 & 25.4 & 27.6 & 935 & 6.6 & 20 & 44.4 & 31229 & 33.7 & 94.0 & 612 \\
\hline Chhattisgarh & 71.04 & 65.4 & 40 & 22.6 & 22 & 969 & 7.2 & NA & 42 & 58297 & 30.4 & 86.3 & 589 \\
\hline Jharkhand & 67.63 & 63.4 & 48 & 22.3 & 24.8 & 948 & 6.9 & 25 & 53.0 & 46131 & 31.2 & 60.1 & 456 \\
\hline Uttarakhand & 79.63 & 65.8 & 50 & 19.2 & 26.7 & 890 & 6.7 & 69 & 63.8 & 103349 & 29.23 & 92.2 & 654 \\
\hline $\begin{array}{l}\text { Madhya } \\
\text { Pradesh }\end{array}$ & 70.63 & 63.8 & 54 & 20.4 & 26.3 & 918 & 8.0 & 99 & 46.6 & 54030 & 31.7 & 78.0 & 651 \\
\hline Orissa & 73.45 & 64.8 & 51 & 14.2 & 19.6 & 941 & 8.4 & NA & 45.0 & 54241 & 32.6 & 75.3 & 394 \\
\hline Rajasthan & 67.06 & 67.5 & 47 & 21.3 & 25.6 & 888 & 6.5 & 17 & 68.0 & 65098 & 14.7 & 78.1 & 1500 \\
\hline $\begin{array}{l}\text { Uttar } \\
\text { Pradesh }\end{array}$ & 69.72 & 63.8 & 50 & 20.2 & 27.2 & 902 & 7.7 & 294 & 72.0 & 37630 & 29.4 & 95.1 & 903 \\
\hline $\begin{array}{l}\text { Combined } \\
\text { Average of } \\
\text { BIMARU } \\
\text { states }\end{array}$ & 70.37 & 65.27 & 47.75 & 20.70 & 24.97 & 924 & 7.25 & 65.50 & 54.35 & 56251 & 29.16 & 82.38 & 719 \\
\hline \begin{tabular}{l|} 
Degree of \\
Correlation \\
w.r.t Literacy
\end{tabular} & & -.255 & .420 & -.646 & -.242 & -.245 & .256 & .066 & .154 & .829 & .126 & .155 & -.258 \\
\hline t-test & & .645 & 1.135 & 2.08 & 1.54 & 1.56 & .645 & .162 & .381 & $3.60^{* *}$ & .311 & .384 & .656 \\
\hline India & 74.04 & 67.5 & 40 & 17.7 & 21.4 & 918 & 7.0 & 3450 & 58.7 & 74380 & 21.9 & 85.5 & 13835 \\
\hline
\end{tabular}

Source: Census of India 2011, latest NFHS-3, Economic Survey 2012-13, 14-15, 16-17 
Table 2 Status of Women With Respect to Social Sector Development Year 2016-17

\begin{tabular}{|c|c|c|c|c|c|c|c|c|c|c|c|c|}
\hline 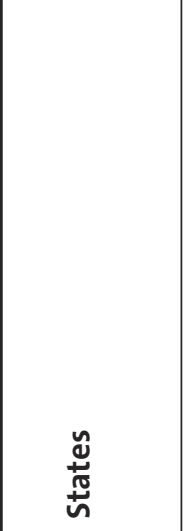 & 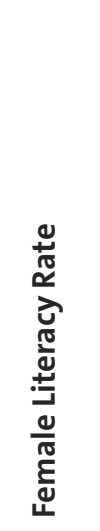 & 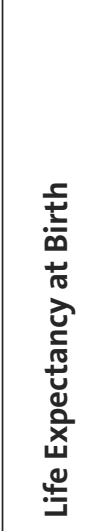 & 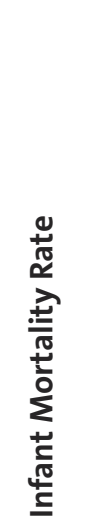 & 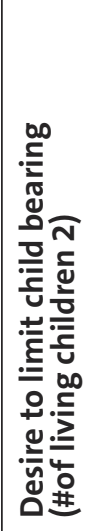 & 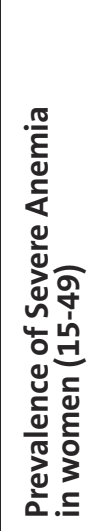 & 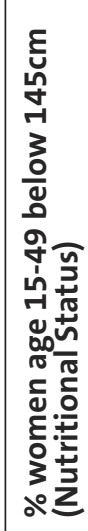 & 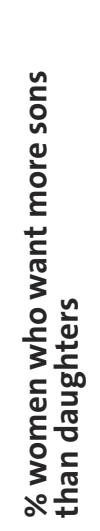 & 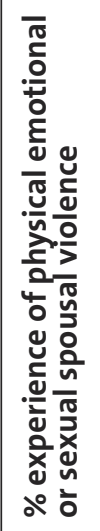 & 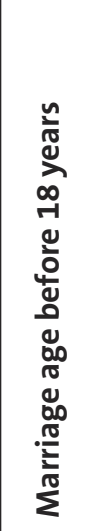 & 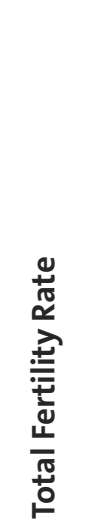 & 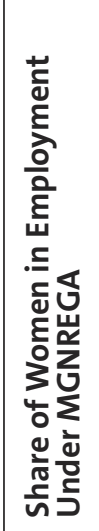 & 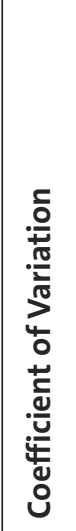 \\
\hline Bihar & 53.33 & 68.0 & 43 & 60.2 & 1.0 & 15.9 & 39.2 & 60.8 & 63.7 & 3.4 & 28.82 & $64 \%$ \\
\hline Chhatisgarh & 60.59 & 64 & 59 & 75.3 & 1.9 & 11.9 & 32.8 & 32.3 & 50.5 & 2.8 & 30 & $72 \%$ \\
\hline Jharkhand & 56.21 & 62 & 55 & 64.3 & 1.3 & 18 & 28.1 & 40.9 & 60.2 & 3 & 29.4 & $63 \%$ \\
\hline Uttarakhand & 70.70 & 69 & 40 & 86.3 & 1.5 & 7.5 & 20.7 & 29.8 & 26.0 & 2.5 & 32 & $88 \%$ \\
\hline $\begin{array}{l}\text { Madhya } \\
\text { Pradesh }\end{array}$ & 60.02 & 65.5 & 55 & 81.9 & 1.0 & 8.4 & 30.8 & 49.1 & 52.6 & 2.9 & 42.48 & $72 \%$ \\
\hline Orissa & 64.36 & 65.9 & 52 & 82.3 & 1.5 & 13.1 & 24.2 & 41.2 & 37.5 & 2.1 & 38.60 & $73 \%$ \\
\hline Rajasthan & 52.66 & 70.0 & 49 & 72.8 & 2.5 & 5.0 & 34.3 & 50.2 & 58.4 & 2.8 & 69.20 & $68 \%$ \\
\hline $\begin{array}{l}\text { Uttar } \\
\text { Pradesh }\end{array}$ & 59.06 & 65.2 & 52 & 64.2 & 1.6 & 14.4 & 33.5 & 45.0 & 52.2 & 3.1 & 16.98 & $71 \%$ \\
\hline $\begin{array}{l}\text { Combined } \\
\text { average } \\
\text { BIMARU } \\
\text { states } \\
\end{array}$ & 59.61 & 66.20 & 50.62 & 73.41 & 1.54 & 11.77 & 30.45 & 43.66 & 50.14 & 2.82 & 35.93 & $70 \%$ \\
\hline \begin{tabular}{|l|} 
Degree \\
Correlation \\
w.r.t Literacy \\
\end{tabular} & & .039 & -.218 & .776 & -.147 & -.236 & -.856 & -.766 & -.966 & -.690 & -0.294 & \\
\hline t-test & & .095 & .547 & $2.89^{* *}$ & .364 & .594 & $4.09^{* *}$ & $3.24^{* *}$ & $9.2^{* *}$ & 2.34 & .756 & \\
\hline India & 65.46 & 69.3 & 42 & 83.2 & 1.8 & 11.4 & 22.4 & 39.7 & 45.6 & 2.3 & 47.98 & $72 \%$ \\
\hline
\end{tabular}

Source : Census of India 2011, Latest NFHS-3, Economic Survey 2012-13,14-15,16-17. Note: significance at 5\%. 
Table 3 Literacy Differential

\begin{tabular}{|c|l|c|c|c|c|}
\hline Serial No. & $\begin{array}{l}\text { STATE } \\
\text { NAME }\end{array}$ & $\begin{array}{c}\text { MALE } \\
\text { LITERACY }\end{array}$ & $\begin{array}{c}\text { FEMALE } \\
\text { LITERACY }\end{array}$ & $\begin{array}{c}\text { OVERALL } \\
\text { LITERACY } \\
\text { RATE }\end{array}$ & $\begin{array}{c}\text { LITERACY } \\
\text { DIFFERENTIAL } \\
\text { INDEX }\end{array}$ \\
\hline 1 & BIHAR & 73.39 & 53.33 & 63.82 & 0.31 \\
\hline 2 & JHARKHAND & 78.45 & 56.21 & 67.63 & 0.33 \\
\hline 3 & UTTARPRADESH & 79.24 & 59.06 & 69.72 & 0.29 \\
\hline 4 & RAJSTHAN & 80.51 & 52.66 & 67.06 & 0.42 \\
\hline 5 & CHHATTISGRAH & 81.45 & 60.59 & 71.04 & 0.29 \\
\hline 6 & MADHYA PRADESH & 80.53 & 60.02 & 70.63 & 0.29 \\
\hline 7 & UTTARAKHAND & 88.33 & 70.70 & 79.63 & 0.22 \\
\hline 8 & ORRISSA & 82.40 & 64.36 & 73.45 & 0.25 \\
\hline & India & 82.10 & 65.46 & 74.04 & 0.22 \\
\hline
\end{tabular}

Source: As per Table $1 \& 2$

Status of women with respect to social sector development reveals that female literacy as compared to overall literacy plays a vital role for the development of the society. It is found that (Table 2) Rajasthan and Bihar are: lowest with respect to female literacy as compared to a combined average of EAG states; had a negative correlation with infant mortality; prevalence of severe anemia in women; percentage of women age 15-49 below $145 \mathrm{~cm}$; percentage of women who want more sons than daughters; percentage of experience of physical, emotional or sexual violence; marriage age before 18 years and total fertility rate. It means with the increase in female literacy all the above mentioned indicators shows declining trends. Hence, we can say that in this scenario, women's education is the major factor behind women empowerment. It is seen that marriage before 18 years shows highest negative (.966) correlation with female literacy. It means girls want to continue their education rather than preferred marriage. Not even in this indicator, percentage of women who want more sons than daughters also shows negative correlation (.856). The reason behind is that, in rural areas people believe that more sons mean more division in property. However, girls are studying more and earning well and bringing prosperity home. On the other hand, low level of literacythe economically poor look to children as helping hands to their family. Hence, it is seen that there is no bar on number of children in uneducated poor families as they think children aare assets not liabilities.

Though overall literacy shows a positive correlation with the infant mortality rate, close analysis of the female literacy rate reveals a negative correlation with infant mortality revealing a negative correlation. The fact of the matter is that the states where their women are more literate and aware, they are having a low infant mortality rate. So the policy maker should emphasize increased girl education because if a girl is educated then the coming generation also get educated.

The female work participation rate is considered an important indicator of gender development. Basically, it is the level of prosperity; socio-economic set-up; literacy; etc. which leads to a higher female work participation rate (FWPR). However, a high work participation rate need not imply higher gender status in all circumstances. In this study, we observed that there is a weak negative correlation share of women in employment under MGNREGP with literacy. It means there is no space for educated women in such a project and is only associated with the uneducated women. So, we can say that to promote female literacy Government should start some programs for educated women under MGNREGP.

Further, the only one indicator which showed positive result when related to female literacy was desire to limit child bearing (.776). We can say that along with literacy some other factor like 
medical aids over the years has increased and hence the death rate has decreased, which has change the mentality of rural population that having more children will result in surviving children. In old days medical facilities were not good compared to modern times. On the other hand, due to expenses on the higher side, urban couples are also restricting having children .

It can be concluded that in order to reduce gender disparity the government should set up more educational institutions. To increase enrollment of girls in schools in rural areas measures should be adopted by the government to provide safety for the school going girls. The Maharashtra government has started special buses so girls from other states may also attend such type of facility; focus on girl's safety to increase the education level. Secondly, female literacy can be improved by increasing the country's infrastructure like school to be accessible to village and community. In many villages there is not even a middle school; no girls toilet; due to all these problems and social taboos people don't want to send girls in or out of the village for study. Thus we can say that the real development of an area in fact depends upon education, because education leads to human capital formation and helps in awakening of the masses. Further, government initiatives; availability of educational infrastructure; social awareness; prosperity; exposure and the location of the area from the state headquarter appear to determine the level of literacy in an area.

Problems of Regional disparities on the level of economic development are almost universal. Their extent may differ in different economy. But their existence can hardly be challenged seriously in any nation of respectable size. To keep this thing in mind, we have tried to analyse the relative aspect of female literacy rate in EAG states. It was observed that Jharkhand and Bihar having fewer disparities (63\% and 64\%) as compared to rest of the BIMARU states. On the other hand, Uttarakhand, Orissa and M.P. (88\%, $73 \%$ and 72 $\%$ respectively) had higher disparity.

\section{Discussion}

The HDI (Human Development Index) reported in the Human Development Report (HDR) published by United Nations Development Program (UNDP) is relatively a better method of measuring growth than using just gross domestic product (GDP). HRI captures progress in terms of basic capabilities to live a long and healthy life'; to be educated and knowledgeable; to enjoy a decent economic standard of life / Quality of Life. According to the latest HDR 2018, the HDI for India was 0.638, with an overall global ranking of 130 (out of the 189 countries). However, there should be no room for complacency as India is still in the medium human development category with countries like Sri Lanka, Thailand, the Philippines, Egypt and Indonesia and our results which are showing a low degree of correlation of literacy and other indicators of development is more or less prove this. The social system, structure and social taboos also play a major role for all these indicators mentioned above. All EAG states even show a low level of life expectancy at birth than the national average of 67.5 years in 2011. While developed states like Punjab, Haryana, Gujarat, Kerala, Maharashtra continued to have life expectancy above the national average. These glaring disparities between different states of India are widening as inter-personal disparities are also on the rise.

\section{Conclusion}

So far the Government has tried to reduce disparities in these states by following inclusive development. But inclusive development means social as well as financial inclusion. Because the present study reveals that though some backward states have a little bit better literacy level, this level even shows negative or low degree of correlation with other indicators of development. Despite more than six decades of planned economic development a large part of the population, particularly landless agricultural laborers of backward states, marginal farmers, SCs, STs, and OBCs, suffer social and financial exclusion. Though government's policies are directed to uplift backward states so as to enable everyone to reap benefits of growth the goal remains a mirage. The present study established a close connection between social inclusion and financial inclusion. Inclusive development also includes the objective of reduction of inter-state disparities. The study reveals that socio-economic performance of the states has been varied. While EAG states have performed well in terms of female lit- 
eracy when it is correlated with other women's empowerment indicators Vis-à-vis overall literacy. These backward states have their own socioeconomic problems for which there is no uniform solution, making the implementation of policy measures difficult. Adding to this are inherent problems of lower growth rate and lack of infrastructure and development. Social inclusion is closely linked to financial inclusion and corrective steps are needed in this direction.

\section{References:}

1. PRADHAN PRASAD H (1988) Agrarian Violence in Bihar, Economic and Political Weekly, Vol. XIII, No.22, May 30, pp.847848.

2. SUCHA SINGH G, GILL K (1988) Development Process, Regional Disparity and policy in India, paper presented in a seminar held in Punjabi University, Patiala, (S.M.I.E., VII, 1188).

3. JAGDISH N. BHAGWATI and SUKHMOY CHAPRAVARTY (1960) Contribution to India Economic Analysis, The American Review, Vol. LIX, No.4, Part 2 (Supplement), Sept., pp. 28.

4. BOSE. ASHISH The man who coined the term, (www.mint.com).

5. DON'T CALL THEM BIMARU STATES NOW (2010) Hindustantimes.com. July 19, 2010.

6. SAMPATH R K (1977) Inter-State inequalities in income in India, 1951-71, Indian Journal of Regional Service“, Vol. 9, Number- I.

7. KHANNA K (2010) Socio-Economic Development in Punjab-A Comparative Study of Border and Non-Border Areas, Prakash Publishing House, ISSN-978-93-82529-06-4, 2010, pp.167. 